\title{
Novel clinicopathological and molecular characterization of metanephric adenoma: a study of 28 cases
}

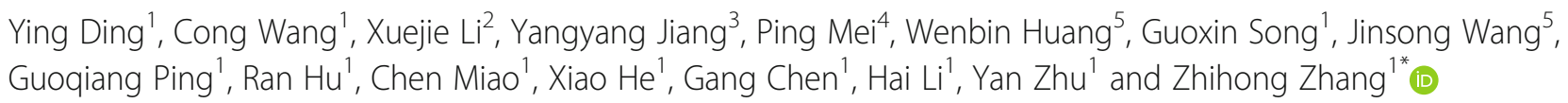

\begin{abstract}
Background: Metanephric adenoma is a rare, benign renal neoplasm with occasional misdiagnosis. However, its molecular characterization is not fully understood.

Methods: In this study, we use the hybrid capture-based Next-Generation Sequencing to sequence a panel of 295 well-established oncogene or tumor suppressor genes in 28 cases of MA patients in China. Novel

clinicopathological markers associated with the mitogen-activated protein kinase (MAPK) pathway in metanephric adenoma were detected by immunohistochemistry.

Results: It was found that except for BRAF (22/28) mutations (c.1799 T > A, p.V600E), NF1 (6/28), NOTCH1 (5/28), SPEN (5/28), AKT2 (4/28), APC (4/28), ATRX (3/28), and ETV4 (3/28) mutations could also be detected. Meanwhile, a novel and rare gene fusion of STARD9-BRAF, CUX1-BRAF, and LOC100507389-BRAF was detected in one MA patient. In addition, although MEK phosphorylation was normally activated, the phosphorylation level of ERK was low in metanephric adenoma cases. Highly expressed p16 and DUSP6 may have contributed to these results, which maintained MA as a benign renal tumor.
\end{abstract}

Conclusions: This study provides novel molecular and pathological markers for metanephric adenoma, which could improve its diagnosis and increase the understanding of its pathologic mechanism.

Keywords: Metanephric adenoma, Next-generation sequencing (NGS), BRAF V600E mutation, Mitogen-activated protein kinase (MAPK) pathway

\section{Background}

Metanephric adenoma (MA) is a rare, benign renal neoplasm, as it exhibits a low proliferation rate and favorable outcome [1]. MA patients are usually asymptomatic, incidentally discovered, and occur across different age groups with a female predominance (female: male $=2: 1$ ) $[1,2]$. Histologically, MA is comprised of primitive metanephric tubular epithelial cells, which are arranged tightly as small acini structures $[3,4]$. Papillary, tubular, and glomeruloid growth patterns can be identified in most MA cases [4]. Tumor cells have round nuclei, scant cytoplasm, extremely low mitotic activity, and rare necrosis [5].

\footnotetext{
* Correspondence: zhangzh@njmu.edu.cn

${ }^{1}$ Department of Pathology, The First Affiliated Hospital of Nanjing Medical

University, 300 Guangzhou Road, Nanjing 210029, China

Full list of author information is available at the end of the article
}

However, it is difficult to distinguish MA from other malignant renal cell carcinoma using imaging studies [1]. Besides, the histopathological diagnosis of MA could be challenging $[3,6]$. There is similar morphology between MA and other renal tumors such as epithelial-predominant nephroblastoma (Wilms tumor) and the solid variant of type 1 papillary renal cell carcinoma (PRCC), both of which demonstrate aggressive behavior. These similar morphologies seriously influence clinical diagnosis and therapy $[6,7]$. Therefore, in some questionable cases, especially core needle biopsy samples, immunohistochemistry and fluorescence in situ hybridization (FISH) analysis may be useful in the identification of MA. Udager et al. showed that positive immunostaining of WT1 and CD57, negative of CK7 and AMACR could be a characteristic of MA [6]. Meanwhile, it

(C) The Author(s). 2018 Open Access This article is distributed under the terms of the Creative Commons Attribution 4.0 International License (http://creativecommons.org/licenses/by/4.0/), which permits unrestricted use, distribution, and reproduction in any medium, provided you give appropriate credit to the original author(s) and the source, provide a link to the Creative Commons license, and indicate if changes were made. The Creative Commons Public Domain Dedication waiver (http://creativecommons.org/publicdomain/zero/1.0/) applies to the data made available in this article, unless otherwise stated. 
was found that MA lacks copy number variants of chromosomes 7, 17, and Y, which are typical in type 1 PRCC [8].

Recently, genetic analysis has revealed the novel molecular characteristics of MA. It was demonstrated that missense mutation of BRAF V600E could be detected in approximately $90 \%$ of this kidney tumor subtype [3]. In addition, other somatic mutations at BRAF exon 15, including a V600D missense mutation and a V600D and K601 L double mutation were also reported [6]. Oncogene $B R A F$ encodes a serine/threonine kinase protein, which could be activated by RAS kinase and subsequently phosphorylate MEK kinase to involve the mitogen-activated protein kinase (MAPK) signaling pathway, thereby regulating cell division and differentiation [9]. However, the BRAF V600E mutation could improve BRAF kinase activity and sustain the activation of downstream kinase MEK, which occurs in some human malignancies, such as melanoma, papillary thyroid carcinoma, colonic adenocarcinoma, pulmonary cancer, Langerhans cell histiocytosis, and pleomorphic xanthoastrocytomas to stimulate tumor growth $[10,11]$. However, in some BRAF V600E-mutated indolent neoplasms such as melanocytic nevi and MA, the MAPK cascades are activated as well as that in malignant tumors, but their progression proceeds slowly [12]. Its underlying mechanism has not been fully understood. Increased tumor suppressor p16 (INK4 $\alpha$ ) expression in these BRAF V600E-mutated indolent or benign neoplasms may partly explain this phenomenon, which causes cell cycle arrest and senescence $[13,14]$. Nevertheless, as BRAF V600E mutation is quite rare or even absent in other common renal tumors, it could be used as a molecular marker for the detection of MA.

In this study, we generated a retrospective cohort of 28 MA cases from multiple pathology centers in China to identify more histopathological and molecular features of this rare tumor within the Asian population. Using gene analysis based on Next-Generation Sequencing (NGS), the genetic profiles of MA were described. Meanwhile, novel histopathological markers in MA were also investigated to further explore its possible development patterns.

\section{Methods}

\section{Patients and samples}

Thirty-six cases originally diagnosed as MA were collected from the surgical pathology files of nine participating institutions based in China between 2012 and 2016. Slides stained with hematoxylin and eosin (H\&E) from all original cases were reviewed by two expert pathologists who were blinded to both the clinical and the genetic results. To compare to morphologic mimics, 15 cases of solid variant papillary renal cell carcinoma and 15 cases of epithelial-predominant nephroblastoma were also analyzed. A total of twenty-eight MA cases were confirmed. Clinical parameters, pathological data, and follow-up information of these twenty-eight MA cases were systematically collected. The study was approved by the Ethics Committee of the First Affiliated Hospital of Nanjing Medical University (No. 2016-SRFA-011, the ethics committee did not require additional informed consent to be obtained for this retrospective study).

\section{DNA preparations and NGS analysis}

Formalin fixed paraffin-embedded (FFPE) tissue blocks were used for DNA isolation using the QIAamp DNA FFPE Tissue Kit (QIAGEN). Briefly, $4 \mu \mathrm{m}$ sections were made: the tumor area and the adjacent normal pericarcinous tissue were divided on H\&E-stained slides, and tumor content $>70 \%$ were separated for subsequent DNA isolation. DNA concentration and fragmentation were examined to ensure DNA quality.

For NGS analysis, DNA samples were profiled using a commercially available, capture-based targeted sequencing panel (Burning Rock Biotech Ltd., Guangzhou, China), targeting 295 genes and spanning $1.5 \mathrm{Mb}$ of human genomic regions, including 65 drug targets, 107 well-established oncogene or tumor suppressor genes, and 12 tumor-relevant signaling pathway kinases (Additional file 1: Table S1). All genes were referred to COSMIC, OncoKB and ClinVar database [15]. Indexed samples were sequenced on the Miseq500 Desktop Sequencer instrument (Illumina, Inc., CA, US) with pair-end reads. Sequencing data were mapped to the human genome (hg19) using BWA aligner 0.7.10. Local alignment optimization, variant calling, and annotation were performed using GATK 3.2, MuTect, and VarScan. Variants at loci with a depth of less than 100 were filtered out using the VarScan fpfilter pipeline. A minimum of 5 supporting reads were needed for INDELs and 8 supporting reads were needed for SNV calling. According to the ExAC, 1000 Genomes, dbSNP and ESP6500SI-V2 databases, variants with population frequencies of over $0.1 \%$ were grouped as germline mutation. Remaining somatic variants were annotated with ANNOVAR and SnpEff v3.6. DNA translocation analysis was performed using both Tophat2 and Factera 1.4.3.

\section{Gene mutations in different renal carcinomas from cBioPortal for Cancer genomics database}

To compare the gene mutation spectrum of MA and other renal tumors, especially Wilms tumor and PRCC, which have morphological similarities with MA, we collected the gene mutation data from cBioPortal for Cancer Genomics database [16, 17]. In cBioPortal database, 499 cases of clear cell RCC were originally from TCGA database (https://tcga-data.nci.nih.gov), 102 cases of Wilms tumor were from TARGET data (https://ocg. cancer.gov/programs/target/data-matrix), 293 cases of PRCC were from TCGA database. 


\section{Amplification refractory mutation system and sanger sequencing}

Instances of the BRAF V600E mutation were confirmed using the $\mathrm{ADx}-\mathrm{ARMS}^{\oplus} B R A F$ Mutation Assay Kit (AmoyDx, China) by ARMS (Amplification Refractory Mutation System) and Scorpions technologies. Using flanking sequence-specific primers (forward: 5'-TTTG TGAATACTGGGAACTATGAAA-3', reverse: 5'-TCAT CCTAACACATTTCAAGCC-3') and HotStarTaq DNA polymerase (Qiagen), BRAF exon 15 was amplified by PCR. The PCR products were detected with bidirectional Sanger sequencing using the Prism ${ }^{\circledR} 3100$ Genetic Analyzer (ABI, CA, US). The resulting chromatograms were analyzed with Chromas software, version Pro 2.23 and compared with a reference sequence for $B R A F$ exon 15 (NM_004333.4). Commercially available BRAF V600E-mutated or wild-type human genomic DNA were utilized as positive and negative controls respectively.

\section{Immunohistochemistry}

Tissue sections were deparaffinized and rehydrated, and antigen was retrieved by citrate buffer in a pressure cooker at $125{ }^{\circ} \mathrm{C}$ for $4 \mathrm{~min}$. The primary antibodies that were used are listed in Table 1. After antigen retrieval, sections were incubated with different primary antibodies at $4{ }^{\circ} \mathrm{C}$ overnight, then stained by Dako EnVision + Systerm and DAB chromogen (Dako) incubation following their protocols. Positive and negative controls were used for each antigen.

The extent of immunohistochemical staining was double-blind evaluated by two expert pathologists. Tumor cells that showed less staining $(0 \%)$ were considered negative, while tumor cells with 1 to $100 \%$ staining were positive. Over $50 \%$ of the tumor cells stained positivity were scored as diffuse and strong (3+); 26 to $50 \%$ were evaluated as intermediate and moderate $(2+)$; and between 1 and $25 \%$ were scored as focal and weak $(1+)$.

\section{Results}

Clinicopathologic features of a retrospective MA cohort

Thirty-six cases originally diagnosed as MA from nine pathology centers in China were analyzed in this study. After subsequent diagnosis, it was found that eight cases were misdiagnosed: two cases were reclassified as solid variant papillary renal cell carcinoma, one was epithelial-predominant nephroblastoma, one was tubulocystic carcinoma, one was renal mucinous tubular and spindle cell carcinoma (MTSCC), one was juxtaglomerular cell tumor (reninoma), one was renal oncocytoma, and one was renal solitary fibrous tumor. In which, tubulocystic carcinoma, MTSCC, reninoma, renal oncocytoma and renal solitary fibrous tumor have different morphological characterizes with MA, which were excluded after double-blinded review by two expert pathologists from our department. The remainders, two cases of PRCC and one case of Wilms tumor, which exerted similar morphological features with MA, were further identified by immunohistochemical study and $B R A F$ mutations detection using qPCR. Thus, twenty-eight confirmed MA cases were available in this study (female: male $=18: 10$ ); the age of patients at diagnosis ranged from 12 to 80 years (median age $=39$ year) . Sixteen of the patients developed MA in the right kidney, whereas 12 of the patients had MA in the left kidney. All MA tissues were obtained from partial or total nephrectomy specimens. The largest dimension of tumors ranged from 2 to $7 \mathrm{~cm}$ (median size $=3.1 \mathrm{~cm}$ ). Except for 'not available' cases $(n=3)$, all the MA

Table 1 Antibodies used

\begin{tabular}{|c|c|c|c|c|}
\hline Name of antibody & Protein target & Manufacturer & Catalog & Dilution used \\
\hline CK7 & Cytokeratin 7 & Fuzhou Maixin Biotech & Kit-0021 & $1: 1$ \\
\hline P504S & alpha-methylacyl-CoA racemase (AMACR), P504S & Fuzhou Maixin Biotech & RMA-0546 & $1: 1$ \\
\hline WT-1 & Wilms tumor 1 & Fuzhou Maixin Biotech & MAB-0678 & $1: 1$ \\
\hline CD57 & human natural killer-1 & Fuzhou Maixin Biotech & MAB-0257 & $1: 1$ \\
\hline P53 & p53 & Fuzhou Maixin Biotech & MAB-0674 & $1: 1$ \\
\hline $\mathrm{BCL} 2$ & B-cell lymphoma 2 & Fuzhou Maixin Biotech & RMA-0660 & $1: 1$ \\
\hline CCND1 & Cyclin-D1 & Abcam & ab16663 & $1: 200$ \\
\hline P16 & P16INK4A & Fuzhou Maixin Biotech & MAB-0673 & $1: 1$ \\
\hline$p-E R K$ & phosphorylated Thr202/Tyr204-p44/42 MAPK & Cell Signaling Tech & 4370 & $1: 100$ \\
\hline ERK & total p44/42 MAPK & Cell Signaling Tech & 4695 & $1: 100$ \\
\hline p-MEK & phosphorylated MEK1/2 (Ser221) & Cell Signaling Tech & 2338 & $1: 100$ \\
\hline MEK & total MEK1/2 & Cell Signaling Tech & 4694 & $1: 100$ \\
\hline DUSP4/MKP-2 & Dual specificity protein phosphatase 4/MAP kinase phosphatase-2 & Abcam & ab216576 & $1: 50$ \\
\hline DUSP6/MKP-3 & Dual specificity protein phosphatase 6/MAP kinase phosphatase-3 & Abcam & ab54940 & 1:50 \\
\hline
\end{tabular}


patients $(n=25)$ have survived until now. Patient and tumor characteristics are summarized in Additional file 2: Table S2.

Microscopically, all MAs exhibit small uniform epithelial cells. These tumors were found with scant cytoplasm, dark nuclei without nucleoli, no mitotic figure was found. Most cells were arranged in small acinar structures, and simple tubules, papillary, glomeruloid growth patterns, and solid structures could be also identified (Fig. 1).

\section{Deep-sequencing reveals novel mutations in MA}

To explore the genetic profile of MA, we used the hybrid capture-based NGS to sequence a panel of 295 well-established oncogene or oncosuppressors. In each analyzed MA patient, 85 somatic mutational events were detected. The vast majority of mutation types were missense and synonymous variants (56.8 and 26.3\%, respectively), while a smaller percentage was represented by copy number gain, indel, stop-gained, splice-region variants, or fusion (8.1, 2.1, 2.3, 1.2 and $3.2 \%$, respectively). In summary, the somatic mutation spectrum and mutation load (14.5/Mb) of MA was quite different from several other common types of renal carcinoma, such as renal clear cell carcinoma, Wilms tumor, and papillary renal cell carcinoma (Table 2, Fig. 2a).

It was shown that in MA, BRAF was the most frequently mutated gene (23 samples in a total of $28 \mathrm{MA}$ cases, 82\%), and NF1 (6/28), NOTCH1 (5/28), SPEN (5/ 28), AKT2 (4/28), APC (4/28), ATRX (3/28), and ETV4 $(3 / 28)$ mutations were also frequently detected. Other gene mutations, such as FANCD2, FAT3, KDM6A, KDR, TET2, and TSC2, occurred twice in this MA cohort, which was quite different from other common types of renal carcinoma (Fig. 2b, Table 3). Meanwhile, some gene copy number gains, such as AKT2, MET, ETV4, CCND1 and FGFR1 were also detected in these MA samples (data not shown).

As previously reported, high frequency mutation of $B R A F$ could be detected in MA [3]. In this study, we found $22 \mathrm{MA}$ patients possessing a p.V600E mutation of $B R A F$ exon 15, a substitution of thymidine by adenine $($ GTG $\rightarrow$ GAG) at codon 600. Meanwhile, a novel and rare STARD9-BRAF, CUX1-BRAF and LOC100507389-$B R A F$ gene fusion was detected in one case. In this case, none of the other $B R A F$ mutation variants was detected. All BRAF mutations have been confirmed using RT-PCR and Sanger sequencing (data not shown). In these BRAF V600E mutated MA patients (female: male $=16: 6$ ), the median age was 40 years (ranging from 25 to 73 years) and the greatest dimension ranged from 2.5 to $7 \mathrm{~cm}$ (median $=3.2 \mathrm{~cm}$ ). However, among the five cases with the wild-type $B R A F$ gene, we found a striking gender difference (female: male $=1: 4$ ), and the median age of BRAF wild-type patients tended to be 29 years (ranging from 12 to $47)$, which was smaller than BRAF V600E-mutated MA patients $(p<0.01)$. In addition, tumor size in BRAF wild-type cases ranged from 2 to $5.5 \mathrm{~cm}$ (median $=2.2$ ); this value was also less than that in BRAF V600E-mutated patients $(p<0.05$, Table 4$)$. Although the morphological features were similar between MA and the other eight renal carcinoma cases which were initially misdiagnosed in this study, none of these renal carcinoma cases showed a BRAF exon 15 mutation (data not shown).
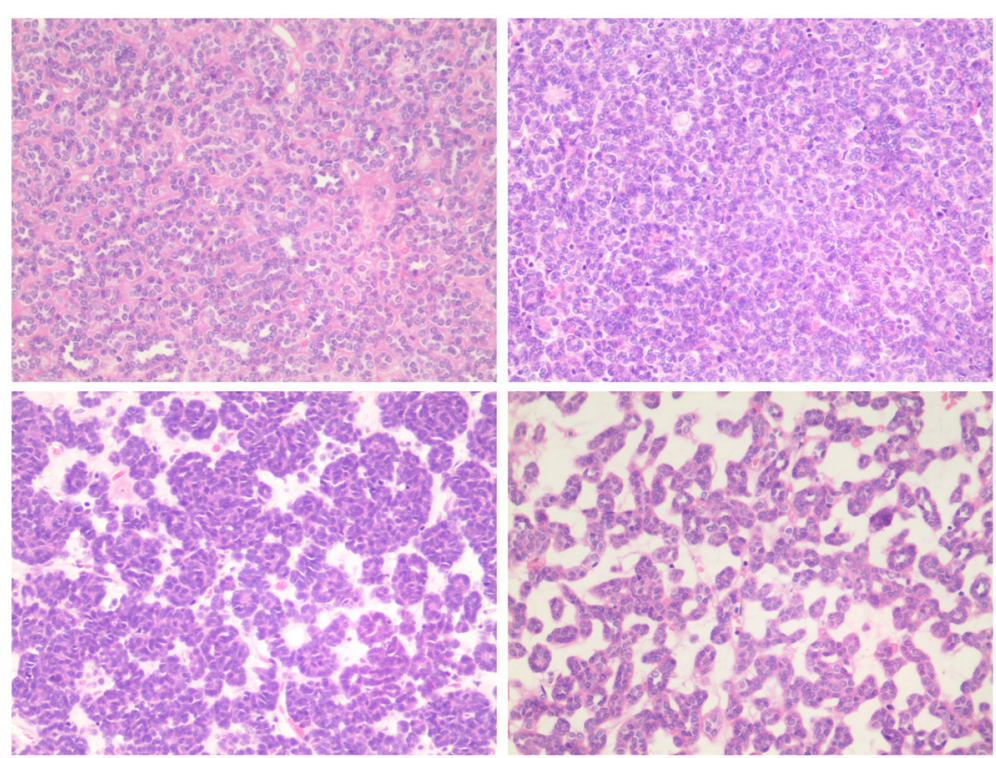

Fig. 1 Representative images of H\&E stataining of MA, 200X 
Table 2 The somatic mutation spectrum in different renal carcinoma

\begin{tabular}{|c|c|c|c|c|c|c|c|c|c|c|c|c|}
\hline & \multicolumn{3}{|c|}{$\begin{array}{l}\text { Present study } \\
(n=28)\end{array}$} & \multicolumn{3}{|c|}{$\begin{array}{l}\text { Renal Clear Cell Carcinoma } \\
(n=499)\end{array}$} & \multicolumn{3}{|c|}{$\begin{array}{l}\text { Wilms Tumor } \\
(n=102)\end{array}$} & \multicolumn{3}{|c|}{ Papillary Renal Cell Carcinoma $(n=293)$} \\
\hline & Gene & Mutant & Freq & Gene & Mutant & Freq & Gene & Mutant & Freq & Gene & Mutant & Freq \\
\hline 1 & BRAF & 23 & $82 \%$ & VHL & 235 & $51 \%$ & TP53 & 15 & $15 \%$ & MET & 23 & $7 \%$ \\
\hline 2 & NF1 & 6 & $21 \%$ & PBRM1 & 158 & $36 \%$ & HLA-DQB1 & 11 & $7 \%$ & КМT2C & 20 & $6 \%$ \\
\hline 3 & NOTCH1 & 5 & $18 \%$ & MUC4 & 142 & $21 \%$ & CTNNB1 & 8 & $7 \%$ & MUC4 & 20 & $5 \%$ \\
\hline 4 & SPEN & 5 & $18 \%$ & SETD2 & 60 & $13 \%$ & CDK11A & 6 & $6 \%$ & SETD2 & 19 & $6 \%$ \\
\hline 5 & AKT2 & 4 & $14 \%$ & BAP1 & 44 & $10 \%$ & DROSHA & 7 & $6 \%$ & KIAA1109 & 17 & $6 \%$ \\
\hline 6 & APC & 4 & $14 \%$ & KDM5C & 30 & $7 \%$ & TMPRSS13 & 5 & $4 \%$ & BAP1 & 16 & $5 \%$ \\
\hline 7 & ATRX & 3 & $11 \%$ & MTOR & 23 & $5 \%$ & ADCK5 & 4 & $4 \%$ & $A R$ & 16 & $5 \%$ \\
\hline 8 & ETV4 & 3 & $11 \%$ & PABPC1 & 20 & $5 \%$ & WT1 & 4 & $4 \%$ & KMT2D & 15 & $5 \%$ \\
\hline 9 & FANCD2 & 2 & $7 \%$ & AHNAK2 & 19 & $4 \%$ & SIX1 & 4 & $4 \%$ & PCLO & 14 & $4 \%$ \\
\hline 10 & FAT3 & 2 & $7 \%$ & PTEN & 19 & $4 \%$ & MAP3K4 & 4 & $4 \%$ & FAT1 & 13 & $4 \%$ \\
\hline 11 & KDM6A & 2 & $7 \%$ & ATM & 18 & $3 \%$ & ACTB & 3 & $3 \%$ & NEFH & 13 & $4 \%$ \\
\hline 12 & KDR & 2 & $7 \%$ & KMT2C & 17 & $4 \%$ & ZNF880 & 3 & $3 \%$ & WDFY3 & 13 & $4 \%$ \\
\hline 13 & NOTCH3 & 2 & $7 \%$ & MAGEC1 & 16 & $4 \%$ & ZNF595 & 3 & $3 \%$ & SYNE1 & 13 & $4 \%$ \\
\hline 14 & TET2 & 2 & $7 \%$ & MUC6 & 16 & $3 \%$ & DGCR8 & 3 & $3 \%$ & CUL3 & 13 & $4 \%$ \\
\hline 15 & TSC2 & 2 & $7 \%$ & LRP1B & 15 & $4 \%$ & AGRN & 3 & $3 \%$ & ZNF814 & 13 & $3 \%$ \\
\hline 16 & & & & PCLO & 15 & $4 \%$ & MADCAM1 & 4 & $3 \%$ & ALMS1 & 13 & $3 \%$ \\
\hline 17 & & & & SYNE1 & 15 & $4 \%$ & HYDIN & 3 & $3 \%$ & DNAH8 & 12 & $4 \%$ \\
\hline 18 & & & & ARID1A & 14 & $3 \%$ & & & & CUBN & 12 & $4 \%$ \\
\hline 19 & & & & KMT2D & 14 & $3 \%$ & & & & PBRM1 & 12 & $4 \%$ \\
\hline 20 & & & & MUC2 & 14 & $3 \%$ & & & & PCF11 & 12 & $4 \%$ \\
\hline
\end{tabular}

In addition, it should be noticed that one germline BRCA1 (NM_007300.3) mutation which was likely pathogenic (c.2286A > T (p.Arg762Ser)) was found in a male MA patient. This patient also had a somatic BRAF V600E, APC L662I, and FANCD2 N791S missense mutation. He had no personal history of breast cancer, prostatic cancer, or pancreatic cancer, and no family history from his paternal or maternal branch was provided.

\section{Immunohistochemical analysis}

Most of the MA tumors showed the expected staining pattern with negative CK7, AMACR, and positive WT1, CD57 (Fig. 3, Table 5). Only six cases (6/28, 21.4\%) exhibited a discordant immunophenotype: two were focally positive for CK7 (CK7 +/-, AMACR -, WT1 +, and CD57 +), three were negative for WT1 (CK7 -, AMACR -, WT1 -, and CD57 +), and one was negative for CD57 (CK7 -, AMACR -, WT1 +, and CD57 -) (Table 5). Because MA is a slow growing tumor and rarely, if ever, exhibits aggressive behavior, we also analyzed specific markers that are closely associated with tumor cell growth and apoptosis, such as tumor suppressor TP53, anti-apoptosis protein BCL2, and cell-cycle related protein CCND1. Most of the MA cases exhibited the same staining pattern: TP53 -, BCL2 +, and CCND1 - (Fig. 4,
Table 5). There were five cases $(5 / 28,17.9 \%)$ that showed different immunophenotypes (TP53 -, BCL2 -, and CCND1 -). These specific immunohistochemical results were summarized in Table 5. Meanwhile, in BRAF V600E-mutated MA, BCL2-positive cases were significantly higher than those in BRAF wild-type patients (Table 4).

It was reported that BRAF V600E induces senescence via regulation of p16 (INK4 $\alpha)$ in some indolent or benign neoplasms [18]. Therefore, the expression of p16 $(\mathrm{INK} 4 \alpha)$ protein in MA cases was also detected. It was shown that the vast majority of MA patients showed nuclear p16 (INK4 $\alpha)$ immunoreactivity ranging from $1+$ to $3+$; only 4 cases showed negative or weak nuclear staining (Fig. 4, Table 5). Moreover, p16 (INK4 $\alpha$ )-positive cases were significantly higher in BRAF V600E-mutated MA cases in comparison with those in the BRAF wild-type cases (Table 4).

Because of the high frequency of $B R A F$ mutations in $M A$, we further investigated the status of MAPK signaling, the expression of phosphorylated MEK (p-MEK), total MEK (t-MEK), phosphorylated ERK (p-ERK), and total ERK ( $t$-ERK). These were observed by immunostaining in the $28 \mathrm{MA}$ cases, including 5 BRAF wild-type and 23 BRAF-mutated cases (Fig. 5, Table 5). Positive 


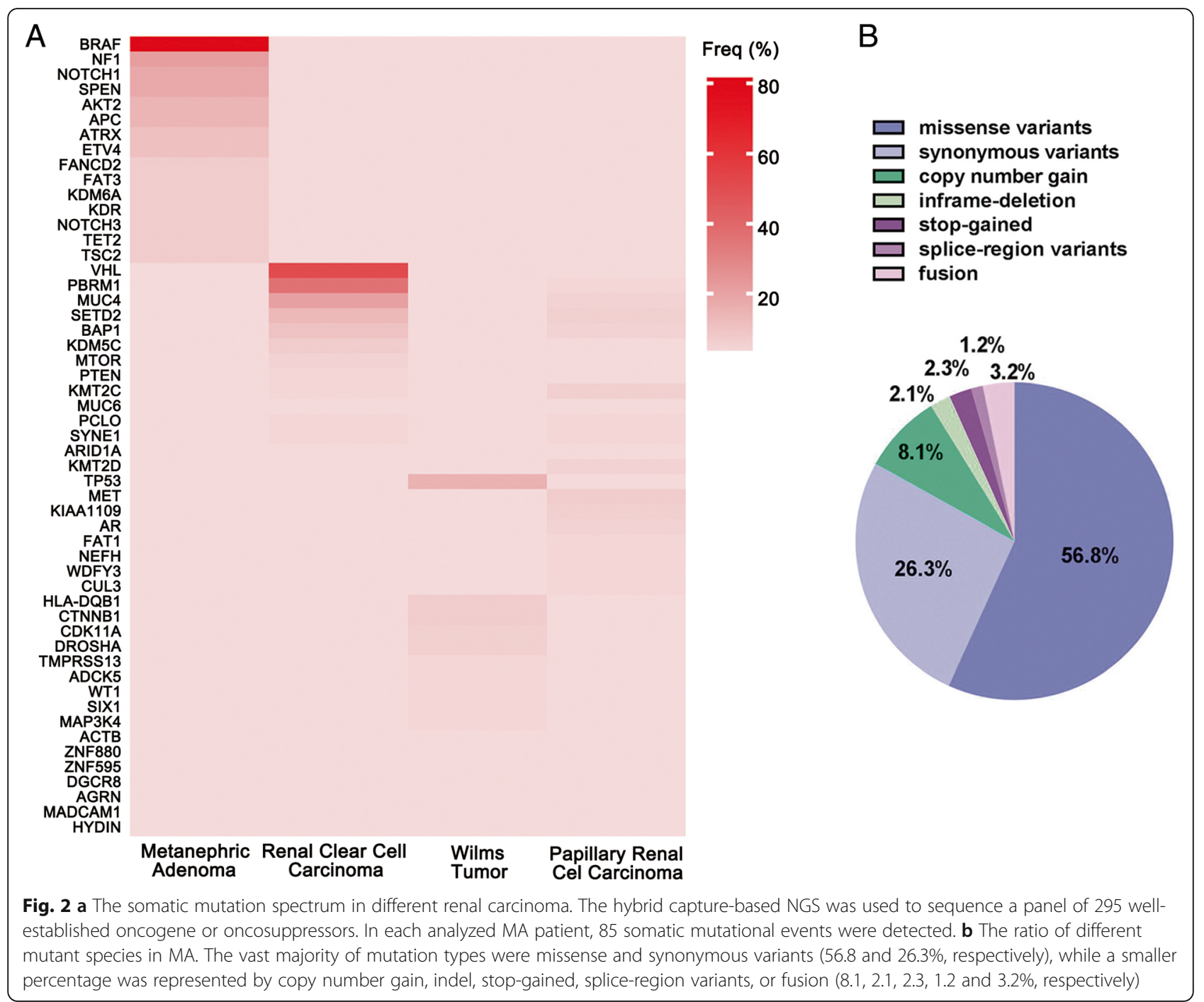

staining for $\mathrm{p}$-MEK, $\mathrm{t}-\mathrm{MEK}$, and $\mathrm{t}$-ERK was detected in the most MA cases. The staining of $t$-MEK and $t$-ERK positive tumor cells ranged from $1+$ to $3+$, indicating diffuse, moderate, and strong cytoplasmic expression. However, although p-MEK staining (ranged from $1+$ to $2+)$ exhibited moderate nuclear staining in all 28 cases of MA, the nuclear staining for p-ERK was negative (15/ $28,53.6 \%)$ or weakly $(1+, 12 / 28,42.9 \%)$ expressed among the different cases (Fig. 5, Table 5). In contrast to MA cells, morphologically normal kidney cortices adjacent to the tumors, including glomeruli, endothelial cells, and a subset of kidney tubules, demonstrated normally expressed and high levels of p-ERK, p-MEK, t-ERK and t-MEK (data not shown).

Suppressed ERK activation with normal MEK phosphorylation in MA drew our attention. Thus, some regulator genes which target ERK were investigated. It was found that except p16 (INK4 $\alpha$ ), a member of the DUSPs superfamily, DUSP6 was diffusely expressed in most of the MA cases, ranging from $1+$ to 3+ (Fig. 5, Table 5). However, no significant difference in p-ERK nor DUSP6 was found between BRAF V600E-mutated and BRAF wild-type MA cases (Table 5). Besides, less DUSP6 staining was detected in the morphologically normal kidney cortex adjacent to the tumors and other ERK regulators such as DUSP4 (Fig. 5), PTPRR and p62 (data not shown), which were less expressed in the MA cells.

\section{Discussion}

It is known that there can be similar histopathological features between MA and some other renal tumors [5, 19]. Thus, novel genetic analysis, including BRAF V600E mutation in MA, could improve the diagnosis of this benign renal tumor. However, except for approximately $10 \%$ of the wild-type genotype, other BRAF mutation sites such as V600D, V600 K, V600R, and $\mathrm{K} 601 \mathrm{~L}$ also exist in MA patients [6, 20]. We further analyzed those $B R A F$ wild-type cases of MA. All five cases of MA which had 
Table 3 Gene altered in MA

\begin{tabular}{|c|c|c|c|c|c|c|}
\hline Gene & $\begin{array}{l}\text { Number of } \\
\text { mutation } \\
\text { events } \\
\text { (frequency) }\end{array}$ & Exon_Rank & $\begin{array}{l}\text { Missense or } \\
\text { stop-gained } \\
\text { mutations }\end{array}$ & Base mutation & $\begin{array}{l}\text { Synonymous } \\
\text { or intronic } \\
\text { mutations }\end{array}$ & Base mutation \\
\hline BRAF & 23 & 15 & $\begin{array}{l}\text { p.V600E, LOC100507389- } \\
\text { BRAF, STARD9-BRAF, } \\
\text { CUX1-BRAF }\end{array}$ & $\begin{array}{l}\text { C.1799 T > A, chrom3:142634278_ } \\
\text { 7:140492322, chrom15:42936216_ } \\
\text { 7:140492968, chrom7:101809365_ } \\
\text { 7:140492220 }\end{array}$ & 1 & 1 \\
\hline NF1 & 6 & $43,46,32$ & p.G1403S, p.Y2285* & c. $4207 G>A, c .6855 C>A$ & p.S2152= & c.6456 T >C \\
\hline $\mathrm{NOTCH}$ & 5 & $29,32,14$ & $\begin{array}{l}\text { p.D1808N, p.H2018Q, } \\
\text { p.D740N }\end{array}$ & $\begin{array}{l}\text { c. } 5422 \mathrm{G}>\mathrm{A}, \mathrm{c} .6054 \mathrm{C}>\mathrm{A}, \\
\text { c. } 2218 \mathrm{G}>\mathrm{A}\end{array}$ & 1 & 1 \\
\hline SPEN & 5 & 11,2 & p.R807H, p.R128C & c. $2420 G>A, c .382 C>T$ & p.K926= & c. $2778 \mathrm{~A}>\mathrm{G}$ \\
\hline AKT2 & 4 & NA & 1 & & cn_amp & 1 \\
\hline APC & 4 & 16 & p.L662I & c. $1984 C>A$ & p.P1634= & c. $4902 \mathrm{G}>\mathrm{A}$ \\
\hline ATRX & 3 & 9 & 1 & 1 & $\begin{array}{l}\text { p.T899=, } \\
\text { p.S651= }\end{array}$ & $\begin{array}{l}\text { c. } 2697 G>A, \\
\text { c. } 1953 \mathrm{~T}>\mathrm{G}\end{array}$ \\
\hline ETV4 & 3 & NA & 1 & 1 & cn_amp & 1 \\
\hline FANCD2 & 2 & 25,30 & p.N791S, p.T981। & c. $2372 A>G$, c. $2942 C>T$ & 1 & 1 \\
\hline FAT3 & 2 & 20,23 & p.R3849Q & c. $11546 G>A$ & p.Y4222= & c. $12666 C>T$ \\
\hline KDR & 2 & 10,15 & p.W460 L, p.1753V & c. $1379 \mathrm{G}>\mathrm{T}, \mathrm{c} .2257 \mathrm{~A}>\mathrm{G}$ & 1 & 1 \\
\hline $\mathrm{NOTCH} 3$ & 2 & 4,24 & p.A198V & C. $593 \mathrm{C}>\mathrm{T}$ & p.P1331= & c.3993G > A \\
\hline TET2 & 2 & 11 & p.E1973K, p.N1765 K & c. $5917 G>A, c .5295 C>G$ & 1 & 1 \\
\hline TSC2 & 2 & $30,35,5$ & p.V1144 M, p.E1513K & c. $3430 \mathrm{G}>\mathrm{A}, \mathrm{c} .4537 \mathrm{G}>\mathrm{A}$ & 1 & 1 \\
\hline ABL1 & 1 & 4 & 1 & 1 & p.L217= & c.649 T > C \\
\hline ALOX12B & 1 & 12 & p.A525T & c. $1573 G>A$ & 1 & 1 \\
\hline AMER1 & 1 & 2 & p.G149_A156del & $\begin{array}{l}\text { c.446_469delGAGCCACAGAG } \\
\text { AAAGCTGTGGCTG }\end{array}$ & 1 & 1 \\
\hline ARID1A & 1 & 1 & 1 & 1 & p.A281= & c. $843 G>A$ \\
\hline ASXL1 & 1 & 12 & p.Q778* & c. $2332 C>T$ & 1 & 1 \\
\hline AURKB & 1 & 6 & p.G161R & c. $481 G>A$ & 1 & 1 \\
\hline$A X L$ & 1 & 2 & p.R71Q & c. $212 \mathrm{G}>\mathrm{A}$ & 1 & 1 \\
\hline BCORL1 & 1 & 3 & p.P312S & c.934C > T & 1 & 1 \\
\hline CCND1 & 1 & NA & 1 & 1 & cn_amp & 1 \\
\hline CD79A & 1 & 2 & 1 & 1 & p.T65= & C. $195 \mathrm{C}>\mathrm{T}$ \\
\hline $\mathrm{CDH} 1$ & 1 & 9 & p.D433N & c. $1297 \mathrm{G}>\mathrm{A}$ & 1 & 1 \\
\hline CDK12 & 1 & 13 & 1 & 1 & p.S1191= & c. $3573 A>G$ \\
\hline DIS3 & 1 & 11 & p.V509 L & c. $1525 G>C$ & 1 & 1 \\
\hline DOT1L & 1 & 24 & p.G1087s & c. $3259 G>A$ & 1 & 1 \\
\hline EP300 & 1 & 2 & 1 & 1 & p.Y207= & c.621C > T \\
\hline EPHA3 & 1 & 7 & p.A515T & c. $1543 G>A$ & 1 & 1 \\
\hline EPHA5 & 1 & 5 & 1 & 1 & p.Y437= & $\mathrm{C} .1311 \mathrm{~T}>\mathrm{C}$ \\
\hline ERBB2 & 1 & 3 & 1 & 1 & p.P122= & $c .366 \mathrm{G}>\mathrm{A}$ \\
\hline ERBB4 & 1 & 27 & p.A1130S & $c .3388 G>T$ & 1 & 1 \\
\hline $\mathrm{EZH} 2$ & 1 & 2 & p.R18C & c. $52 \mathrm{C}>\mathrm{T}$ & 1 & 1 \\
\hline FGFR1 & 1 & NA & 1 & 1 & cn_amp & NA \\
\hline FGFR4 & 1 & 18 & p.D785H & c. $2353 G>C$ & 1 & 1 \\
\hline GRIN2A & 1 & 3 & p.V122I & c. $364 G>A$ & 1 & 1 \\
\hline HRAS & 1 & 4 & 1 & 1 & p.D108= & c. $324 C>T$ \\
\hline
\end{tabular}


Table 3 Gene altered in MA (Continued)

\begin{tabular}{|c|c|c|c|c|c|c|}
\hline Gene & $\begin{array}{l}\text { Number of } \\
\text { mutation } \\
\text { events } \\
\text { (frequency) }\end{array}$ & Exon_Rank & $\begin{array}{l}\text { Missense or } \\
\text { stop-gained } \\
\text { mutations }\end{array}$ & Base mutation & $\begin{array}{l}\text { Synonymous } \\
\text { or intronic } \\
\text { mutations }\end{array}$ & Base mutation \\
\hline IKBKE & 1 & 6 & p.R134C & c. $400 \mathrm{C}>\mathrm{T}$ & 1 & 1 \\
\hline IL7R & 1 & 5 & p.A199G & c. $596 C>\mathrm{G}$ & 1 & 1 \\
\hline INHBA & 1 & 2 & p.K45R & c. $134 A>G$ & 1 & 1 \\
\hline KAT6A & 1 & 15 & 1 & 1 & p.E993del & c.2977_2979delGAG \\
\hline KDM5A & 1 & 23 & 1 & 1 & p.G1200 fs & c.3597dupA \\
\hline KDM6A & 1 & 5 & p.Y143C & c. $428 \mathrm{~A}>\mathrm{G}$ & 1 & 1 \\
\hline KMT2D & 1 & 10 & 1 & 1 & p.P556= & c. $1668 \mathrm{G}>\mathrm{T}$ \\
\hline MAP2K1 & 1 & 10 & p.Q354H & C. $1062 A>C$ & 1 & 1 \\
\hline MET & 1 & NA & 1 & 1 & cn_amp & NA \\
\hline MTOR & 1 & 28 & 1 & 1 & p.A1388= & c. $4164 C>T$ \\
\hline NCOR1 & 1 & 4 & 1 & 1 & p.L133= & c.399G $>$ A \\
\hline NF2 & 1 & 5 & 1 & 1 & p.R160= & c. $478 \mathrm{C}>\mathrm{A}$ \\
\hline NPM1 & 1 & 7 & p.V192 M & c. $574 G>A$ & 1 & 1 \\
\hline NSD1 & 1 & 5 & 1 & 1 & p.K513= & C.1539G > A \\
\hline NTRK1 & 1 & 8 & p.N323S & c. $968 A>G$ & 1 & 1 \\
\hline PAK3 & 1 & 1 & p.S31G & c. $91 A>G$ & 1 & 1 \\
\hline PARP2 & 1 & 8 & p.E231K & c. $691 \mathrm{G}>\mathrm{A}$ & 1 & 1 \\
\hline PARP4 & 1 & 31 & 1 & 1 & p.R1332= & c. $3996 C>$ T \\
\hline PAX5 & 1 & 6 & 1 & 1 & p.L234= & c. $700 \mathrm{C}>\mathrm{T}$ \\
\hline PIK3C2G & 1 & 29 & p.R1316G & c. $3946 A>G$ & 1 & 1 \\
\hline PIK3CG & 1 & 8 & 1 & 1 & p. $1879=$ & c. $2637 C>T$ \\
\hline PMS2 & 1 & 9 & p.R304T & $\mathrm{C} .911 \mathrm{G}>\mathrm{C}$ & 1 & 1 \\
\hline PRDM1 & 1 & 5 & p.H409Q & c. 1227 C > A & 1 & 1 \\
\hline RAD52 & 1 & 9 & p.A248T & c. $742 \mathrm{G}>\mathrm{A}$ & 1 & 1 \\
\hline RET & 1 & 7 & 1 & 1 & p.G453= & c.1359G >C \\
\hline RPTOR & 1 & 14 & 1 & 1 & p.N513= & c. $1539 C>T$ \\
\hline SMARCA4 & 1 & 35 & p.R1633Q & c. $4898 \mathrm{G}>\mathrm{A}$ & 1 & 1 \\
\hline sox 10 & 1 & 4 & p.T240P & c. $718 \mathrm{~A}>\mathrm{C}$ & 1 & 1 \\
\hline TSC1 & 1 & 13 & p.M425 V & c. $1273 A>G$ & 1 & 1 \\
\hline TSHR & 1 & 5 & p.G132R & c.394G > C & 1 & 1 \\
\hline
\end{tabular}

Abbreviations: chrom chromosome, $c n$ amp copy number gain amplification, del deletion

negative $B R A F$ mutation showed typical morphologic features of MA. Meanwhile, their immunophenotyping were WT-1 +, CD57 +, CK7 -, AMACR -, which were also accorded with the diagnosis of MA [6]. Moreover, these patients received good treatment outcomes and good prognosis, which differs them from malignant renal tumors. We also detected copy number variations of 7, 17 and $\mathrm{Y}$ chromosomes by FISH technology, and found no abnormities among these five cases of MA, which is characteristic of type 1 PRCC (data not shown). All these morphologic features, immunohistochemical patterns, clinical characteristics and long-term prognosis supported that although the $B R A F$ mutation were negative, these five cases still should be identified as MA. However, although negative $B R A F$ exists in MA, considered the high frequency of $B R A F$ mutation improves the diagnosis of MA. It should be noticed that metanephric stromal tumors (MST), another benign renal tumor, and the BRAF V600E mutation were frequently detected [21, 22]. Therefore, finding more pathological and molecular markers is still essential for improving the diagnosis of MA.

In this study, we examined the genetic profiles of MA in a large cohort of Chinese MA patients from multiple pathology centers using NGS-based gene analysis for the first time. Similar to previous studies mainly conducted on Caucasian MA patients [3, 20, 23], it was found that 
Table 4 Patient characteristics between BRAF V600E and BRAF wild-type MA patients

\begin{tabular}{|c|c|c|c|}
\hline \multirow[t]{2}{*}{$n$} & Total & BRAF V600E & $\begin{array}{l}\text { BRAF } \\
\text { wild-type }\end{array}$ \\
\hline & 27 & 22 & 5 \\
\hline Gender & $F: M=9: 18$ & $\mathrm{~F}: \mathrm{M}=5: 17$ & $F: M=1: 4^{*}$ \\
\hline Age range, year & $12 \sim 80$ & $25 \sim 73$ & $12 \sim 47^{* *}$ \\
\hline Median age, year & 39 & 40 & 29 \\
\hline Tumor size, cm & $2 \sim 7$ & $2.5 \sim 7$ & $2 \sim 5.5^{*}$ \\
\hline Median size, $\mathrm{cm}$ & 3.1 & 3.2 & 2.2 \\
\hline BCL2, (negative/positive) & $5 / 22$ & $2 / 20$ & $3 / 2^{* *}$ \\
\hline p16, (negative/positive) & $4 / 23$ & $1 / 21$ & $3 / 2^{* *}$ \\
\hline p-MEK, (negative/positive) & $0 / 27$ & $0 / 22$ & $0 / 5$ \\
\hline p-ERK, (negative/positive) & $15 / 12$ & $13 / 9$ & $2 / 3$ \\
\hline DUSP6, (negative/positive) & $4 / 23$ & $2 / 20$ & $2 / 3$ \\
\hline
\end{tabular}

Abbreviations: $F$ female. $M$ male. ${ }^{*} p<0.05,{ }^{*} p<0.01$ compared to BRAF V600E group. Statistical analysis was performed by Chi-square test

MA patients from Asian populations also have a high rate of mutation in the BRAF V600E site. This finding can further improve the using of BRAF V600E detection in the diagnosis of MA. It should be noticed that a novel STARD9-BRAF, CUX1-BRAF, and LOC100507389-BRAF gene fusion was found at $B R A F$ intron 8 without V600E mutation. As MA is a rare, benign renal tumor, the clinical significance of this novel BRAF gene fusion remains unknown. However, recent studies showed that different $B R A F$ fusions, such as GTF2I-BRAF [24], DGKI-BRAF [25], and TMEM106B-BRAF [26], activated the MAPK pathway, thereby regulating tumor growth in multiple cancers. Therefore, it could be suspected that this novel three-sites BRAF gene fusion also intervenes with the MAPK pathway, which may play an important role in not only MA but also in other malignant tumors.

Using NGS analysis, not only the BRAF V600E mutation, but also other somatic mutations, including NF1, NOTCH1, SPEN, AKT2, APC, ATRX, and ETV4, were found to have a high mutation rate in MA. Thus, the somatic mutation spectrum of MA could be described, which was quite different from several other renal tumors such as renal clear cell carcinoma, renal non-clear cell carcinoma, and papillary renal cell carcinoma. It was known that the histopathological diagnosis of MA faced challenges [19]. In our total thirty-six cases originally diagnosed as MA, eight of them were misdiagnosed. Although these misdiagnosed cases from other participating institutions may be caused by different diagnostic level, similar morphological between MA and other renal carcinomas like Wilms tumor or PRCC increased the difficulty of diagnosis. Thus, clarifying the somatic mutation spectrum could improve the identification of MA in pathological diagnosis, especially in some difficult cases. Although it was confirmed that there was no copy number gain in chromosomes 3, 7, 17, and Y in those 28 MA cases by FISH analysis (data not shown), which is frequently existed in type 1 PRCC [8], NGS results still suggested that approximately $8.1 \%$ copy number gain occurred in total mutations. As it was known, the copy number variants were highly associated with the development of
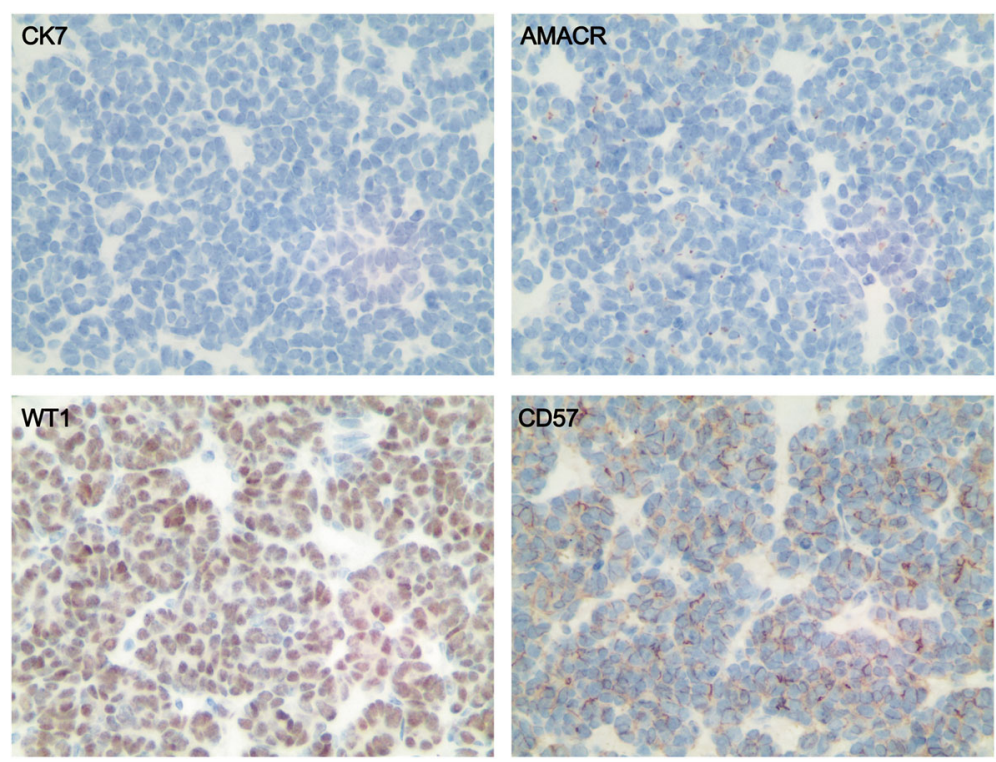

Fig. 3 Immunohistochemical staining for pathological markers CK7, AMACR, WT1 and CD57 (400x) in representative MA tissues. The staining of positive tumor cells ranged from 1+ to $3+$, indicating diffuse, moderate, and strong cytoplasmic expression 
Table 5 Immunohistochemical characteristics

\begin{tabular}{|c|c|c|c|c|c|c|c|c|c|c|c|c|c|c|}
\hline Patient Number & BRAF status & CK7 & AMACR & WT-1 & CD57 & P53 & $\mathrm{BCL} 2$ & CCND1 & P16 & $p$-ERK & ERK & p-MEK & MEK & DUSP6 \\
\hline 1 & BRAF V600E & - & - & $3+$ & $2+$ & - & $3+$ & - & $3+$ & - & $3+$ & $2+$ & $3+$ & $2+$ \\
\hline 2 & BRAF wild-type & - & - & $3+$ & $3+$ & - & - & - & $2+$ & - & $3+$ & $2+$ & $3+$ & $1+$ \\
\hline 3 & BRAF V600E & - & - & $1+$ & $2+$ & - & - & - & $1+$ & - & $2+$ & $1+$ & $2+$ & $1+$ \\
\hline 4 & BRAF wild-type & - & - & $2+$ & $2+$ & - & - & - & $1+$ & - & $2+$ & $1+$ & $3+$ & - \\
\hline 5 & BRAF V600E & - & - & $3+$ & $3+$ & - & $1+$ & - & - & - & $3+$ & $2+$ & $3+$ & $1+$ \\
\hline 6 & BRAF V600E & - & - & $3+$ & $2+$ & - & - & - & $1+$ & - & $2+$ & $1+$ & $2+$ & $1+$ \\
\hline 7 & BRAF V600E & - & - & $1+$ & $2+$ & - & $2+$ & - & $2+$ & $1+$ & $1+$ & $1+$ & $2+$ & $1+$ \\
\hline 8 & BRAF V600E & - & - & $2+$ & $2+$ & - & $2+$ & - & $2+$ & - & $2+$ & $1+$ & $3+$ & - \\
\hline 9 & BRAF V600E & - & - & $3+$ & $3+$ & - & $3+$ & - & $2+$ & $1+$ & $2+$ & $1+$ & $3+$ & $1+$ \\
\hline 10 & BRAF V600E & - & - & $1+$ & $3+$ & - & $2+$ & - & $2+$ & $1+$ & $1+$ & $1+$ & $3+$ & $2+$ \\
\hline 11 & BRAF V600E & - & - & $3+$ & $2+$ & - & $3+$ & - & $3+$ & $1+$ & $2+$ & $1+$ & $2+$ & $2+$ \\
\hline 12 & BRAF V600E & - & - & - & $3+$ & - & $3+$ & - & $3+$ & - & $2+$ & $2+$ & $1+$ & $2+$ \\
\hline 13 & BRAF V600E & - & - & $2+$ & - & - & $3+$ & - & $2+$ & $1+$ & $1+$ & $1+$ & $2+$ & $1+$ \\
\hline 14 & BRAF V600E & - & - & $3+$ & $2+$ & & $2+$ & - & $1+$ & $1+$ & $1+$ & $1+$ & $2+$ & $1+$ \\
\hline 15 & BRAF V600E & - & - & - & $1+$ & - & $3+$ & - & $1+$ & - & $2+$ & $2+$ & $1+$ & $2+$ \\
\hline 16 & BRAF V600E & - & - & $1+$ & $1+$ & - & $2+$ & - & $1+$ & - & $1+$ & $2+$ & $3+$ & - \\
\hline 17 & BRAF wild-type & - & - & $1+$ & $1+$ & - & - & - & - & $1+$ & $2+$ & $1+$ & $3+$ & $1+$ \\
\hline 18 & BRAF V600E & - & - & $1+$ & $1+$ & - & $3+$ & - & $3+$ & - & $3+$ & $1+$ & $3+$ & $1+$ \\
\hline 19 & BRAF V600E & - & - & - & $1+$ & - & $3+$ & - & $2+$ & - & $3+$ & $1+$ & $1+$ & $2+$ \\
\hline 20 & $\begin{array}{l}\text { BRAF Intron8-STARD9/ CUX1/ } \\
\text { LOC100507389 fusion }\end{array}$ & $+/-$ & - & $1+$ & $1+$ & - & $3+$ & - & $3+$ & $1+$ & $2+$ & $1+$ & $2+$ & $1+$ \\
\hline 21 & BRAF V600E & - & - & $1+$ & $1+$ & - & $2+$ & - & $1+$ & - & $1+$ & $1+$ & $3+$ & $1+$ \\
\hline 22 & BRAF V600E & - & - & $1+$ & $1+$ & - & $3+$ & - & $1+$ & 1 & $1+$ & $1+$ & $2+$ & $1+$ \\
\hline 23 & BRAF V600E & $+/-$ & $1+$ & $1+$ & $1+$ & - & $3+$ & - & $2+$ & 1 & $1+$ & $1+$ & $2+$ & $1+$ \\
\hline 24 & BRAF wild-type & - & - & $1+$ & $1+$ & - & $2+$ & - & - & $1+$ & $2+$ & $1+$ & $1+$ & $1+$ \\
\hline 25 & BRAF wild-type & - & - & $1+$ & $1+$ & - & $3+$ & - & - & $1+$ & $3+$ & $2+$ & $2+$ & - \\
\hline 26 & BRAF V600E & - & - & $1+$ & $1+$ & - & $3+$ & - & $1+$ & - & $3+$ & $1+$ & $3+$ & $2+$ \\
\hline 27 & BRAF V600E & - & - & $1+$ & $1+$ & - & $2+$ & - & $2+$ & - & $1+$ & $1+$ & $3+$ & $1+$ \\
\hline 28 & BRAF V600E & - & - & $1+$ & $1+$ & - & $3+$ & - & $1+$ & $1+$ & $1+$ & $1+$ & $1+$ & $1+$ \\
\hline
\end{tabular}

malignancy, such as type 1 PRCC [27]. It was reported that in some cases, which arose as Wilms tumor or PRCC, might develop to be similar in morphology with MA, thereby leading to misdiagnosis [28]. Therefore, improving the diagnosis of MA would be important in the prognosis of patients, and the effect of detected copy number variants in MA should be further identified.

Interestingly, a rare germline $B R C A 1$ mutation was found in one male MA patient without a personal or family history of breast cancer, prostatic cancer, or pancreatic cancer. It was widely known that $B R C A 1 / 2$ are important tumor suppressor genes, which help DNA repair and promote cell apoptosis in breast and other tissues [29]. And certain mutations of $B R C A 1 / 2$ often lead to increasing the risk of breast and ovarian cancer in women [30]. However, BRCA1 mutation was less investigated in MA and other renal carcinomas. After surgical removal, this MA patient was still alive, and no other tumors were found. Because this sole case cannot establish the relationship between this germline $B R C A 1$ mutation and tumor development as MA, the role of this famous tumor suppressor gene in MA requires further evaluation.

Based on the genetic profile of MA, we further investigated the expression of some molecular markers associated with tumor cell survival and the MAPK pathway. Similar to previous studies, we found that MA patients had high rates of BRAF V600E mutation. It was known that BRAF V600E could sustain the activation of its downstream kinase MEK in the MAPK pathway, thereby stimulating cell division and differentiation in some malignancies [31]. Thus, as well as in other indolent neoplasms such as melanocytic nevi [12], the reason for why MA remains benign in the 

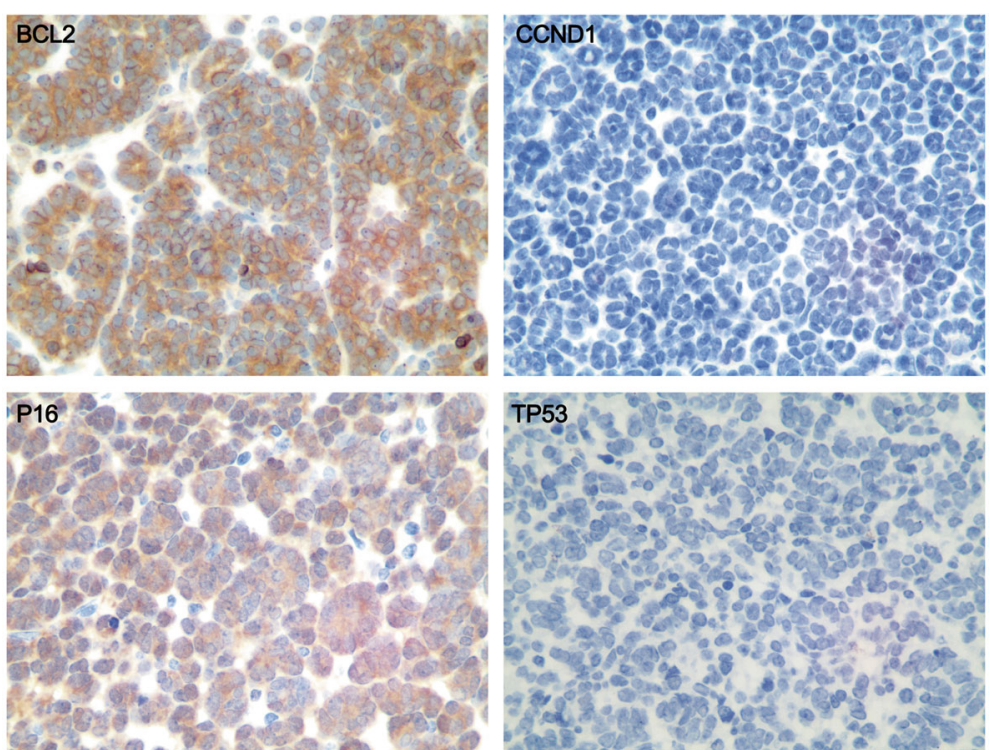

Fig. 4 Immunohistochemical staining for BCL2, CCND1, P16 and TP53 in representative MA tissues, 400x. The staining of positive tumor cells ranged from $1+$ to $3+$, indicating diffuse, moderate, and strong cytoplasmic expression

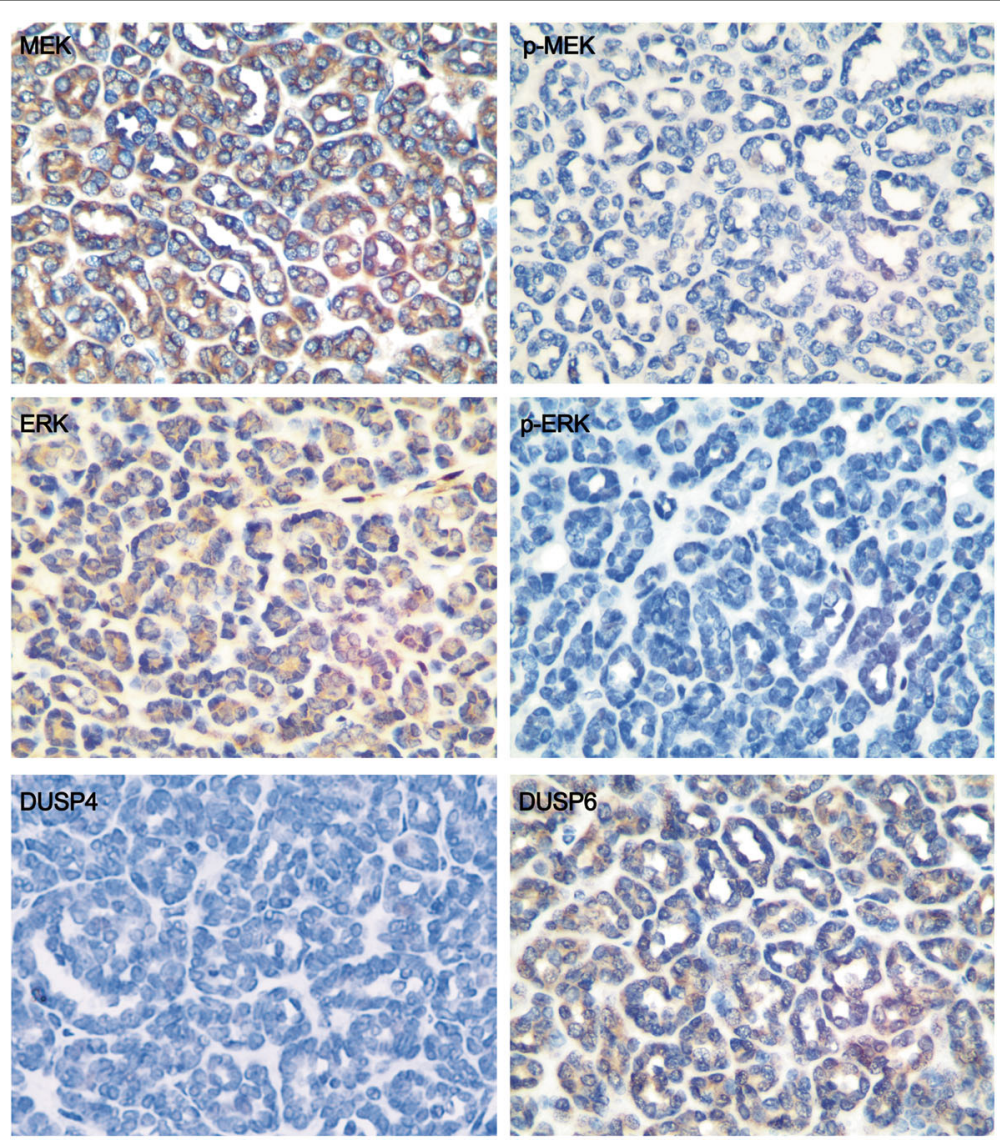

Fig. 5 Immunohistochemical staining for MEK, p-MEK, ERK, p-ERK, DUSP4, DUSP6 in representative MA tissues, 400x. The staining of positive tumor cells ranged from 1+ to 3+, indicating diffuse, moderate, and strong cytoplasmic expression 
presence of a BRAF V600E mutation attracted our attention. One theory partly explained that the BRAF V600E mutation could lead to cell arrest via induction of p16 (INK4 $\alpha$ ). The well-known tumor suppressor p16 (INK4 $\alpha$ ), encoded by the human $C D K N 2 A$ gene, could inhibit the cell cycle from the $\mathrm{G} 1$ to the $\mathrm{S}$ phase, thereby decelerating tumor cell division and leading to cell senescence [32]. In human melanocytes, sustained BRAF V600E mutation could induce cell cycle arrest accompanied by immunoreactivity of p16 (INK4 $\alpha$ ) [18]. Meanwhile, BRAF V600E expression stopped proliferation and induced markers of oncogene-induced senescence including p16 (INK4 $\alpha$ ) in human neural stem cells [33]. Choueiri et al. reported that p-MEK and p-ERK were both positive in BRAF V600E-mutated or wild-type MA patients with the p16 (INK4 $\alpha$ ) senescence marker [3]. In this study, we confirmed that p16 (INK4 $\alpha)$ was highly expressed in most MA patients, which may be important in maintaining MA as an indolent tumor. Differently, our data showed higher p16 (INK4 $\alpha$ )-positive rates in BRAF V600E-mutated MA than in the BRAF wild-type, which increased the relationship between BRAF V600E and the p16 (INK4 $\alpha$ ) senescence marker in those indolent neoplasms. While the human CDKN2A gene is mutated or deleted, which frequently occurred in some malignancies such as melanoma, tumor cells would overcome BRAF V600E-induced senescence and become malignant [34]. However, the development patterns in indolent neoplasms should be complex. Not only p16 (INK4 $\alpha$ ), but other senescence markers such as acidic $\beta$-galactosidase and PAI- 1 , could also be involved in cell senescence induced by a BRAF mutation [14].

Moreover, factors that directly affect the MAPK pathway may also participate in the development of indolent neoplasms. Kim et al. found that ERK phosphorylation was not increased in BRAF V600E-mutated papillary thyroid carcinomas; conversely, phosphorylation decreased, even compared to normal thyroid glands [35]. Therefore, although p-ERK positivity was observed in MA in a previous study, to further investigate the status of the MAPK pathway in MA, we verified MEK and ERK phosphorylation by immunostaining. As we expected, MEK kinase was phosphorylated in both $B R A F$-mutated and wild-type cases. But only $44.4 \%$ of MA cases showed a low grade of p-ERK positivity. In the rest of the cases, the immunoreactivity of p-ERK was weak or entirely negative. Besides, the p-ERK positivity was no different between the $B R A F$-mutated and wild-type MA cases, suggesting that a BRAF mutation causes an irrelevant pathway that blocks the MAPK signal, which may be another important reason for the indolence of MA.

Signals that directly inhibit ERK phosphorylation may explain this phenomenon. It has been reported that the up-regulated expression of MAP phosphatase 3/dual specificity phosphatase family of protein 6 (MKP3/DUSP6), a cytosolic ERK1/2-targeted phosphatase, contributed to the senescence of NRK-52E rat renal tubular epithelial cells via dephosphorylation of ERK1/2 [36]. Meanwhile, DUSP4/MKP2 overexpression is also associated with the aggressive behavior of BRAF V600E-mutated papillary thyroid cancer [37]. Therefore, the expression of ERK1/2 phosphatases DUSP4 and DUSP6 were determined by immunohistochemistry. It was found that DUSP6 was highly expressed, while DUSP4 was less positive in most MA cases. Although the deficiency of MA case number limited the research on the relationship between DUSPs and BRAF V600E mutation, and it was difficult to perform an in vitro experiment for MA, we could still speculate that direct regulation on ERK1/2 phosphorylation by DUSP6 plays an important role in the indolent behavior of MA (Fig. 6).

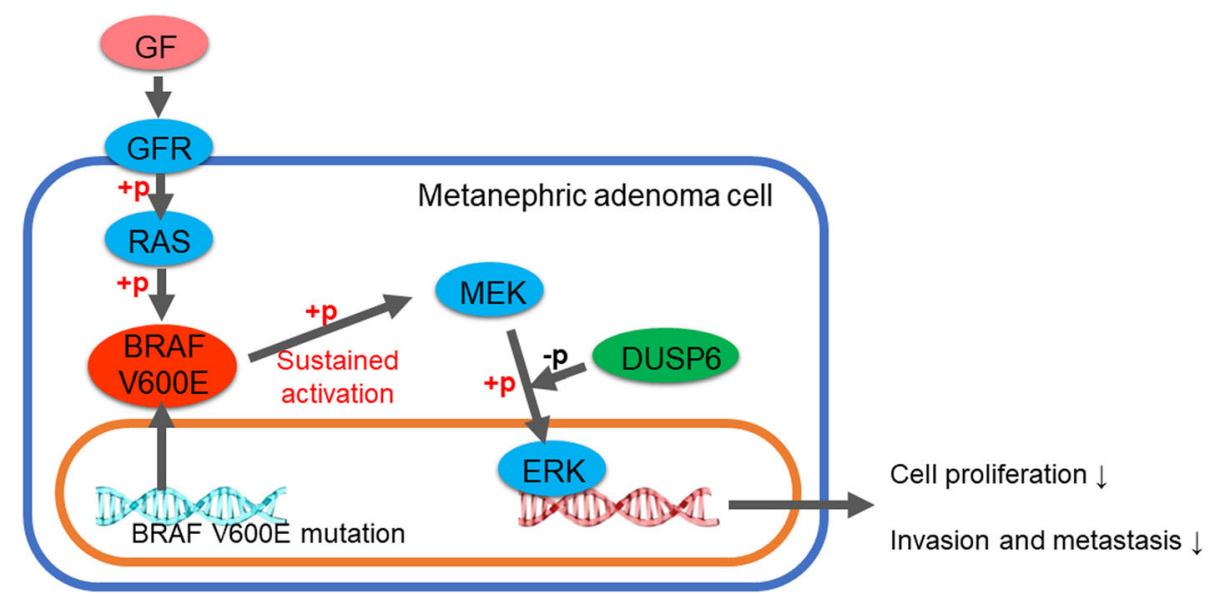

Fig. 6 Pathogenesis of metanephric adenoma 


\section{Conclusions}

In this study, we investigated the genetic profile of MA samples based on a large retrospective cohort of the Asian population for the first time. The establishment of the somatic mutation spectrum could contribute to the diagnosis of MA and other potentially misdiagnosed renal carcinomas. Meanwhile, based on genetic analysis, we suggested that DUSP6-induced ERK1/2 dephosphorylation could be important for the indolent behavior of MA and could also be identified as a potential diagnostic marker for MA. Both novel clinicopathological and molecular features could provide benefits for the diagnosis and better understanding of this rare, potentially misdiagnosed benign renal tumor.

\section{Additional files}

Additional file 1: 295 genes in capture-based targeted sequencing panel. (DOCX 16 kb)

Additional file 2: Patient characteristics. (DOCX $16 \mathrm{~kb})$

\section{Abbreviations}

FFPE: Formalin fixed paraffin-embedded; FISH: Fluorescence in situ hybridization; H\&E: Hematoxylin and eosin; MA: Metanephric adenoma; MAPK: Mitogen-activated protein kinase; MKP3/DUSP6: MAP phosphatase 3/dual specificity phosphatase family of protein 6; MTSCC: Mucinous tubular and spindle cell carcinoma; NGS: Next-Generation Sequencing;

PRCC: Papillary renal cell carcinoma

\section{Acknowledgements}

We thank for the technical support from the Burning Rock Biotech Ltd. for NGS analysis.

\section{Availability of data and material}

The datasets used and/or analyzed during the current study are available from the corresponding author on reasonable request.

\section{Funding}

This work is supported by the National Natural Science Foundation of China (No. 81502089), the Natural Science Foundation of Jiangsu Province (BK20151582, BK20151024), the Fund of the priority Academic Program Development of Jiangsu Higher Education Institution (JX1023-1801), the Training Program of Medical talents of Jiangsu Province (QNRC2016589).

\section{Authors' contributions}

$Z Z$ and YD initiated and coordinated the study and edited the manuscript. YD wrote the initial draft. GS, JW, GP, RH, CM, XH, and GC performed the experiment. $\mathrm{CW}, \mathrm{HL}$ and $\mathrm{YZ}$ contributed to the study concept and design. $\mathrm{XL}, \mathrm{YJ}, \mathrm{PM}$, and $\mathrm{WH}$ contributed to the tissue samples. All authors have read and approved the final version of the manuscript.

\section{Ethics approval and consent to participate}

All patient samples and clinical data using were approved by the Ethics Committee of the First Affiliated Hospital of Nanjing Medical University (2016-SRFA-011). The ethics committee did not require additional informed consent to be obtained for this retrospective study.

\section{Consent for publication}

Not applicable.

\section{Competing interests}

None declared.

\section{Publisher's Note}

Springer Nature remains neutral with regard to jurisdictional claims in published maps and institutional affiliations.

\section{Author details}

${ }^{1}$ Department of Pathology, The First Affiliated Hospital of Nanjing Medical University, 300 Guangzhou Road, Nanjing 210029, China. ${ }^{2}$ Department of Pathology, The First Affiliated Hospital, School of Medicine, Zhejiang Unversity, Hangzhou 310003, China. ${ }^{3}$ Department of Pathology, Shenzhen People's Hospital, Shenzhen 518020, China. ${ }^{4}$ Department of Pathology, Guangdong General Hospital/Guangdong Academy of Medical Sciences, Guangzhou 510000, China. 'Department of Pathology, Nanjing First Hospital, Nanjing 210000, China.

Received: 18 March 2018 Accepted: 30 July 2018

Published online: 16 August 2018

\section{References}

1. Bastide C, Rambeaud JJ, Bach AM, Russo P. Metanephric adenoma of the kidney: clinical and radiological study of nine cases. BJU Int. 2009; 103:1544-8.

2. Paner GP, Turk TM, Clark Jl, Lindgren V, Picken MM. Passive seeding in metanephric adenoma: a review of pseudometastatic lesions in perinephric lymph nodes. Arch Pathol Lab Med. 2005;129:1317-21.

3. Choueiri TK, Cheville J, Palescandolo E, Fay AP, Kantoff PW, Atkins MB, McKenney JK, Brown V, Lampron ME, Zhou M, et al. BRAF mutations in metanephric adenoma of the kidney. Eur Urol. 2012;62:917-22.

4. Davis CJ Jr, Barton JH, Sesterhenn IA, Mostofi FK. Metanephric adenoma. Clinicopathological study of fifty patients. Am J Surg Pathol. 1995;19:1 101-14.

5. Mantoan Padilha M, Billis A, Allende D, Zhou M, Magi-Galluzzi C. Metanephric adenoma and solid variant of papillary renal cell carcinoma: common and distinctive features. Histopathology. 2013;62:941-53.

6. Udager AM, Pan J, Magers MJ, Palapattu GS, Morgan TM, Montgomery JS, Weizer AZ, Hafez KS, Miller DC, Wolf JS Jr, et al. Molecular and immunohistochemical characterization reveals novel BRAF mutations in metanephric adenoma. Am J Surg Pathol. 2015;39:549-57.

7. Kinney SN, Eble JN, Hes O, Williamson SR, Grignon DJ, Wang M, Zhang S, Baldrige LA, Martignoni G, Brunelli M, et al. Metanephric adenoma: the utility of immunohistochemical and cytogenetic analyses in differential diagnosis, including solid variant papillary renal cell carcinoma and epithelial-predominant nephroblastoma. Mod Pathol. 2015;28:1236-48.

8. Brown JA, Anderl KL, Borell TJ, Qian J, Bostwick DG, Jenkins RB. Simultaneous chromosome 7 and 17 gain and sex chromosome loss provide evidence that renal metanephric adenoma is related to papillary renal cell carcinoma. J Urol. 1997;158:370-4.

9. Obaid NM, Bedard K, Huang WY. Strategies for overcoming resistance in Tumours harboring BRAF mutations. Int J Mol Sci. 2017;18

10. Korphaisarn K, Kopetz S. BRAF-directed therapy in metastatic colorectal Cancer. Cancer J. 2016;22:175-8.

11. Kim A, Cohen MS. The discovery of vemurafenib for the treatment of BRAFmutated metastatic melanoma. Expert Opin Drug Discov. 2016;11:907-16.

12. Tan JM, Lin LL, Lambie D, Flewell-Smith R, Jagirdar K, Schaider H, Sturm RA, Prow TW, Soyer HP. BRAF wild-type melanoma in situ arising in a BRAF V600E mutant dysplastic nevus. JAMA Dermatol. 2015;151:417-21.

13. Cisowski J, Sayin Vl, Liu M, Karlsson C, Bergo MO. Oncogene-induced senescence underlies the mutual exclusive nature of oncogenic KRAS and BRAF. Oncogene. 2016;35:1328-33.

14. Raabe EH, Lim KS, Kim JM, Meeker A, Mao XG, Nikkhah G, Maciaczyk J, Kahlert $U$, Jain D, Bar E, et al. BRAF activation induces transformation and then senescence in human neural stem cells: a pilocytic astrocytoma model. Clin Cancer Res. 2011;17:3590-9.

15. Griffith M, Spies NC, Krysiak K, McMichael JF, Coffman AC, Danos AM, Ainscough BJ, Ramirez CA, Rieke DT, Kujan L, et al. CIViC is a community knowledgebase for expert crowdsourcing the clinical interpretation of variants in cancer. Nat Genet. 2017:49:170-4.

16. Cerami E, Gao J, Dogrusoz U, Gross BE, Sumer SO, Aksoy BA, Jacobsen A, Byrne CJ, Heuer ML, Larsson E, et al. The cBio cancer genomics portal: an open platform for exploring multidimensional cancer genomics data. Cancer Discov. 2012;2:401-4. 
17. Gao J, Aksoy BA, Dogrusoz U, Dresdner G, Gross B, Sumer SO, Sun Y, Jacobsen A, Sinha R, Larsson E, et al: Integrative analysis of complex cancer genomics and clinical profiles using the cBioPortal. Sci Signal 2013, 6:pl1.

18. Michaloglou C, Vredeveld LC, Soengas MS, Denoyelle C, Kuilman T, van der Horst CM, Majoor DM, Shay JW, Mooi WJ, Peeper DS. BRAFE600-associated senescence-like cell cycle arrest of human naevi. Nature. 2005;436:720-4.

19. Muir TE, Cheville JC, Lager DJ. Metanephric adenoma, nephrogenic rests, and Wilms' tumor: a histologic and immunophenotypic comparison. Am J Surg Pathol. 2001;25:1290-6.

20. Calio A, Eble JN, Hes O, Martignoni G, Harari SE, Williamson SR, Brunelli M, Osunkoya AO, Wang L, Comperat E, et al. Distinct clinicopathological features in metanephric adenoma harboring BRAF mutation. Oncotarget. 2016;

21. Marsden L, Jennings LJ, Gadd S, Yu M, Perlman EJ, Cajaiba MM. BRAF exon 15 mutations in pediatric renal stromal tumors: prevalence in metanephric stromal tumors. Hum Pathol. 2017:60:32-6.

22. Argani P, Lee J, Netto GJ, Zheng G, Tseh-Lin M, Park BH. Frequent BRAF V600E mutations in Metanephric stromal tumor. Am J Surg Pathol. 2016;40:719-22.

23. Pinto A, Signoretti S, Hirsch MS, Barletta JA. Immunohistochemical staining for BRAF V600E supports the diagnosis of metanephric adenoma. Histopathology. 2015;66:901-4.

24. Tomic TT, Olausson J, Wilzen A, Sabel M, Truve K, Sjogren H, Dosa S, Tisell M, Lannering B, Enlund F, et al. A new GTF2I-BRAF fusion mediating MAPK pathway activation in pilocytic astrocytoma. PLoS One. 2017;12:e175638.

25. Kim HS, Jung M, Kang HN, Kim H, Park CW, Kim SM, Shin SJ, Kim SH, Kim SG, Kim EK, et al. Oncogenic BRAF fusions in mucosal melanomas activate the MAPK pathway and are sensitive to MEK/PI3K inhibition or MEK/CDK4/6 inhibition. Oncogene. 2017;

26. Hsiao SJ, Karajannis MA, Diolaiti D, Mansukhani MM, Bender JG, Kung AL, Garvin $\mathrm{JH}$ Jr. A novel, potentially targetable TMEM106B-BRAF fusion in pleomorphic xanthoastrocytoma. Cold Spring Harb Mol Case Stud. 2017;3:a001396.

27. Kovac M, Navas C, Horswell S, Salm M, Bardella C, Rowan A, Stares M, Castro-Giner F, Fisher R, de Bruin EC, et al. Recurrent chromosomal gains and heterogeneous driver mutations characterise papillary renal cancer evolution. Nat Commun. 2015;6:6336.

28. Arroyo MR, Green DM, Perlman EJ, Beckwith JB, Argani P. The spectrum of metanephric adenofibroma and related lesions: clinicopathologic study of 25 cases from the National Wilms Tumor Study Group Pathology Center. Am J Surg Pathol. 2001;25:433-44.

29. Movassagh M, Mudvari P, Horvath A. Co-occurrence of COMT and BRCA1/2 variants in a population. N Engl J Med. 2017;376:2090-1.

30. Kluska A, Balabas A, Piatkowska M, Czarny K, Paczkowska K, Nowakowska D, Mikula M, Ostrowski J. PALB2 mutations in BRCA1/2-mutation negative breast and ovarian cancer patients from Poland. BMC Med Genet. 2017;10:14.

31. Fang M, Hutchinson L, Deng A, Green MR. Common BRAF(V600E)-directed pathway mediates widespread epigenetic silencing in colorectal cancer and melanoma. Proc Natl Acad Sci U S A. 2016;113:1250-5.

32. Mahajan A. Practical issues in the application of p16 immunohistochemistry in diagnostic pathology. Hum Pathol. 2016:51:64-74.

33. Kumar SM, Dai J, Li S, Yang R, Yu H, Nathanson KL, Liu S, Zhou H, Guo J, Xu $X$. Human skin neural crest progenitor cells are susceptible to BRAF(V600E)induced transformation. Oncogene. 2014;33:832-41.

34. Straume O, Smeds J, Kumar R, Hemminki K, Akslen LA. Significant impact of promoter hypermethylation and the $540 \mathrm{C}>$ T polymorphism of CDKN2A in cutaneous melanoma of the vertical growth phase. Am J Pathol. 2002;161:229-37.

35. Kim SW, Kim HK, Lee Jl, Jang HW, Choe JH, Kim JH, Kim JS, Hur KY, Kim JH, Chung JH. ERK phosphorylation is not increased in papillary thyroid carcinomas with BRAF(V600E) mutation compared to that of corresponding normal thyroid tissues. Endocr Res. 2013:38:89-97.

36. Zhang H, Chi Y, Gao K, Zhang X, Yao J. p53 protein-mediated up-regulation of MAP kinase phosphatase 3 (MKP-3) contributes to the establishment of the cellular senescent phenotype through dephosphorylation of extracellular signal-regulated kinase 1/2 (ERK1/2). J Biol Chem. 2015;290:1129-40.

37. Ma B, Shi R, Yang S, Zhou L, Qu N, Liao T, Wang Y, Wang Y, Ji Q. DUSP4/MKP2 overexpression is associated with BRAF(V600E) mutation and aggressive behavior of papillary thyroid cancer. Onco Targets Ther. 2016;9:2255-63.

\section{Ready to submit your research? Choose BMC and benefit from:}

- fast, convenient online submission

- thorough peer review by experienced researchers in your field

- rapid publication on acceptance

- support for research data, including large and complex data types

- gold Open Access which fosters wider collaboration and increased citations

- maximum visibility for your research: over $100 \mathrm{M}$ website views per year

At $\mathrm{BMC}$, research is always in progress.

Learn more biomedcentral.com/submissions 